\title{
Fuel savings in remote Antarctic microgrids through energy management
}

\author{
Can Berk Saner \\ School of Engineering and Informatics \\ University of Sussex \\ Brighton, UK \\ canberksaner@gmail.com
}

\author{
Spyros Skarvelis-Kazakos \\ School of Engineering and Informatics \\ University of Sussex \\ Brighton, UK \\ S.Skarvelis-Kazakos@sussex.ac.uk
}

\begin{abstract}
Research stations in the Antarctic have their own electrical generation facilities and are not interconnected to any grid. Scarcity of fuel and unavailability of interconnection characterize these Antarctic energy systems as mission-critical isolated microgrids. In this work, an energy management strategy has been proposed for South African Antarctic research station SANAE IV for improving fuel efficiency. The proposed strategy consists of optimal dispatch of generation and installation of a thermal load controller for the supply side, and a novel demand response scheme for the demand side. The system was simulated using HOMER Microgrid Analysis Tool. Results showed an $8.30 \%$ decrease in fuel consumption, which corresponds to 21,876 litres of diesel annually. These savings can be achieved without major capital expenditure or difficult engineering work.
\end{abstract}

Keywords-Microgrids, energy management, demand-side management, power generation dispatch.

\section{INTRODUCTION}

Antarctic is the polar region located in the South Pole. Antarctic is where the coldest, windiest, highest, driest and remotest continent on Earth resides: The Antarctica. Antarctica has never had an indigenous (native) population and has no permanent residents [1]. The population in Antarctica constitutes researchers, short term visitors and tourists. Presumably, the only people that can actually be considered as residents are researchers. As of 2014, there are 82 research stations working year-round or seasonal from 29 different countries, hosting about 4,400 people at its peak [2]. Electricity generators are in use for supplying electrical and thermal energy for all their needs and are critical for life support. Although a few stations have adopted renewable energy sources or hybrid systems, most of them are using conventional generators that are using fossil fuels. Gasoline, diesel and jet fuel are being utilized in order to drive these generators as well as to power water- and land-based vehicles [3].

There are several drawbacks of being dependent on fossil fuel. First of all, the transportation of fuel is not reliable. The cargo ships can only deliver during summer times, and generally once a year. Shipping costs are also extremely high. Some stations are far away from the shore line (e.g. Amundsen - Scott and Vostok stations) which makes the logistics even more challenging. Greenhouse gas emissions, as well as oil spills are also a considerable threat in Antarctica where $70 \%$ of the Earth's fresh water reserves reside. In the light of the above, it is mandatory to use any available energy sources conservatively and efficiently in Antarctica. Therefore, energy management is a key requirement. Each research station in Antarctica has its own electrical generation facilities and they are not interconnected. Hence, for energy generation purposes, each station can be considered as an islanded microgrid. In this paper, an energy management strategy that can be used in an Antarctic microgrid is proposed, under the umbrella of Supply Side Management (SSM) and Demand Side Management (DSM). Supply Side Management (SSM) encompasses the actions that take place in energy generation, transmission and distribution to ensure efficiency in those activities. Demand Side Management (DSM) is the planning, implementation and monitoring of utility activities that are designed to influence consumer's use of energy in terms of time pattern and magnitude.

The strategy proposed in this paper includes the implementation of a thermal load controller for SSM, and a novel demand side management program for DSM that facilitates the efficient use of intermittent renewable energy.

The concept is introduced in Section II, whereas Section III describes the base that was chosen as a case study. The proposed strategy is described in Section IV and Sections V and VI present the modelling and results. Conclusions are drawn in Section VII.

\section{ENERGY MANAGEMENT IN THE ANTARCTIC}

Several studies have been conducted, investigating the possibility of implementation of energy management strategies and integration of renewable energy systems [3],[4],[5],[6],[7]. In [5] a photovoltaic-wind energy system was proposed for French-Italian base Concordia, in addition to existing diesel generation. Solar irradiance data have been measured directly by portable equipment and global irradiance has been calculated via formulae. Wind speed and direction data have been acquired through anemometers. Excess generation would be diverted to a thermal-electrical dump load, which is used for snow melting and heating purposes. Initial capital need for this system has been estimated as $€ 630,000$ with a payback period of 4 years. It is argued that on top of monetary gains, the polluting emissions would be decreased.

A study of renewable energy integration for the Brazilian Comandante Ferraz Antarctic Station was presented in [6]. Assessment of organic solid waste, cogeneration, solar and wind resource has been conducted. It is claimed that gross 
amount of organic solid waste is not sufficient for energy production. Simulations have been performed for wind and solar integration individually, each one with and without the adoption of batteries. It is concluded that the topology of combined heat and power operation, wind power and thermal storage units offered the optimum payback and diesel savings.

Utilization of wind-diesel hybrid generation at the New Zealand Scott Base research station was studied in [7], while introducing a novel demand side management strategy. On top of existing diesel generation facilities, two different wind turbines have been offered with rated power of $100 \mathrm{~kW}$ and 330 $\mathrm{kW}$ in quantities of 3 and 2, respectively. A proposed Demand Side Management (DSM) strategy shifts the load of laundry facilities with respect to the instantaneous renewable penetration. It is estimated that the proposed DSM strategy can save up to 1,600 litres of fuel per year, while installation of two $100 \mathrm{~kW}(200 \mathrm{~kW}$ in total) wind turbines may lead to savings as high as 97,036 litres per year.

Cases of successful energy management actions that have been implemented in Antarctic stations are presented in [3]. These cases include energy efficiency applications such as changing the heating system from electrical to hot water, insulation and other physical implementations to reduce heat leakage from stations. Belgium station Princess Elisabeth is the one and only "zero emission" base in the Antarctic, covering all the thermal and electrical power through $9 \times 6 \mathrm{~kW}$ wind turbines, $300 \mathrm{~m}^{2}$ solar panels, $18 \mathrm{~m}^{2}$ solar thermal panels, battery storage and backup generators.

Another study in [8] investigates the feasibility of wind power in South African base SANAE. Estimates of the availability of wind have been obtained via field experiments and simulations. The $94 \mathrm{~kW}$ snow smelter has been selected as a dump load. It is concluded that the NW100/19 wind turbine is feasible for implementation, producing $100 \mathrm{~kW}$ at $13 \mathrm{~m} / \mathrm{s}$ wind speed. This wind turbine would meet one third of the station's energy demand with an estimated payback period of 10 years. The feasibility of wind power for SANAE IV was assessed again in [9], where a small wind turbine was proposed for the base. The utilization of solar energy at SANAE IV was also evaluated in [10]. It was shown that, since there is virtually no irradiation in winter, solar energy is not useful for space heating. A solar thermal collector has been proposed to be used in the snow melting device. It is mentioned that a 3-4\% decrease in fuel consumption can be obtained annually. The payback period is as short as 6 years, which implies that the solar thermal system may be economically viable.

From the studies above, only [7] touched on the possibility of Demand Side Management (DSM), through a DSM strategy for laundry facilities. This paper discusses the potential of energy management on the demand and the supply side to save precious fuel in the SANAE IV base. The results of this study can be extended to any remote microgrid with scarcity of fuel resource.

\section{THE SANAE IV BASE}

SANAE IV (South African National Antarctic Expedition IV) is a South African Antarctic research station that is established in 1997 [11]. It is located $80 \mathrm{~km}$ away from the edge of Antarctica at Vesleskarvet nunatak, Queen Maud Land region $\left(72.0^{\circ} \mathrm{S}, 2.5^{\circ} \mathrm{W}\right)[10],[11]$. The base consists of three main 2staged blocks (Block A, B and C) and two passages that are connecting the blocks. These units have been raised to 3.5 meters by stilt foundation. It is capable of housing up to 80 residents.

Until 2009, the station's energy demand was met by three standalone diesel generators, two turbo-charged ADE 442T engines rated at $260 \mathrm{~kW}$ and one ADE 442Ti turbo-charged inter-cooled engine rated at $320 \mathrm{~kW}$. These generators are connected to three individual Leroy Somer alternators which are rated at $180 \mathrm{~kW}, 250 \mathrm{kVA}, 400 \mathrm{~V}, 361 \mathrm{~A}$. These motor generator couplings are monitored in terms of output voltage, frequency and generator speed and controlled by a WEXLERGENCON II controller for protection, management, synchronizing and load-sharing. The generators are used in an interchanging manner to enable equal aging. Load sharing among machines is coordinated via a "master and slave" program. Master generator is always in use and the stand-by generator kicks in should the demand exceeds $162 \mathrm{~kW}$ to share the load. Slave generator will be switched off when the demand drops below $140 \mathrm{~kW}$. In extreme cases, i.e. demand over 325 $\mathrm{kW}$, the third generator is switched on. The electrical efficiency of generators is $36.4 \%$ [8]. In this work, this calculated efficiency has been taken as the full load (maximum) efficiency. Excessive heat produced by generators is recovered through water jacket heat exchangers [10]. Recovered heat is used for meeting the thermal demand. Such operation is called Combined Heat and Power (CHP) mode, and it increases the overall efficiency of generators.

After years of research on utilization of renewable energy in SANAE IV base, it has been concluded to utilize a $20 \mathrm{~kW}$ wind turbine. It is mentioned that a small scale, i.e. rated power less than $100 \mathrm{~kW}$, wind turbine has been preferred due to its reliability and simplicity of design [12]. The implementation phase has started in 2009 and the integration has been planned to finalize by 2011 . There was no further information publicly available about this wind turbine (such as wind/power characteristics), current status of integration, or gained benefits.

Distribution of electrical energy in SANAE IV has been divided into three main branches, namely Block A, B and C, along the same line with the physical orientation of the blocks. The rated power of electrical loads adds up to $557.79 \mathrm{~kW}$ which comprises a significant demand. However, a portion of the loads are only used occasionally, such as $30 \mathrm{~kW}$ helicopter-deck hoists and $12 \mathrm{~kW}$ sauna. Rated power of loads for each block is given in Table I.

It is observed that the snow smelter itself covers about $17 \%$ of the total load. This is a vital piece of equipment in the base, which melts the snow to obtain water for drinking, sanitation and cooking. The snow smelter consists of six $15 \mathrm{~kW}$ heating elements and, as a rule of thumb, it is switched on three times a day at about $10 \mathrm{am}, 5 \mathrm{pm}$ and $9 \mathrm{pm}$.

Like every other power system, the SANAE IV base is subject to daily and seasonal alternations in energy consumption. Daily variations arise from usage of different loads in different times and periods. Seasonal variations, on the other hand, are the result of changes in base population and 
weather conditions. There are two main seasons in the Antarctic: takeover and winter. Takeover season is also known as summer season; it is the time when the population at the base reaches its peak. Approximately 80 people occupy the base at summer time, whereas only 10 people are present in the winter period.

TABLE I. ELECTRICAL COMPONENTS IN SANAE IV [13]

\begin{tabular}{|c|c|c|}
\hline Type & Component & Power rating $(\mathrm{kW})$ \\
\hline \multirow{2}{*}{ Generators } & Two turbo-charged ADE $442 \mathrm{~T}$ engines & $\begin{array}{c}260(180 \mathrm{kWe}) \\
\text { each }\end{array}$ \\
\hline & $\begin{array}{l}\text { ADE 442Ti turbo-charged inter-cooled } \\
\text { engine }\end{array}$ & $320(180 \mathrm{kWe})$ \\
\hline Controller & WEXLER-GENCON II controller & - \\
\hline \multirow{7}{*}{$\begin{array}{l}\text { Block A - } \\
\text { total load } \\
92.68 \mathrm{~kW}\end{array}$} & Skirting Heaters & 50.50 \\
\hline & Washing Machines and Driers & 11.56 \\
\hline & Ventilation and Humidification & 7.88 \\
\hline & Lights & 7.48 \\
\hline & Computers & 6.46 \\
\hline & Radio Room and Fire System & 5.80 \\
\hline & Dark Room Urn & 3.00 \\
\hline \multirow{7}{*}{$\begin{array}{l}\text { Block B - } \\
\text { total load } \\
163.67 \mathrm{~kW}\end{array}$} & Kitchen Equipment & 58.65 \\
\hline & Skirting Heaters & 33.00 \\
\hline & Washing Machines and Driers & 17.33 \\
\hline & Lights & 16.59 \\
\hline & Cold and Freezer Room & 11.55 \\
\hline & Dining Room Equipment & 11.35 \\
\hline & Ventilation and Humidification & 15.2 \\
\hline \multirow{9}{*}{$\begin{array}{l}\text { Block C - } \\
\text { total load } \\
301.44 \mathrm{~kW}\end{array}$} & In-line Water Heaters & 120.00 \\
\hline & Snow Smelter & 94.40 \\
\hline & Helicopter-Deck Hoists & 30.00 \\
\hline & Plant Room & 16.60 \\
\hline & Sauna & 12.00 \\
\hline & Ventilation and Humidification & 11.20 \\
\hline & Water Purification & 6.75 \\
\hline & Skirting Heaters & 5.25 \\
\hline & Lights & 5.24 \\
\hline
\end{tabular}

Due to the extreme climate in the Antarctic, a special blend of diesel fuel is being used for the generators named "Special Antarctic Blend" (SAB). It is reported that the price of SAB is almost $80 \%$ higher than ordinary diesel [13]. Monthly consumption of SAB fuel is approximated as more than 22,000 litres which constitutes a considerable cost for the station, especially when the large additional cost of shipping is taken into account.

\section{Proposed Energy MANAGEMENT Strategy}

The load sharing mechanism among generators, explained earlier, might be a simple and efficient approach if there are only diesel generators in use. However, when a renewable energy source with fluctuating output is considered, this approach becomes obsolete. Therefore, a new load dispatch method is necessary. In this study, the HOMER Optimal Dispatch of Generation (ODG) Algorithm was used [14]. The principle of the algorithm is to identify the needs of the system and operate the sources based on minimizing running costs. In this project, the cost has been considered as solely fuel consumption since the costs involved in power system operation like operating, maintenance and replacement costs are unknown. Therefore, the algorithm dispatches the generation in order to minimize the fuel consumption. Further energy management measures are explained as follows.

\section{A. Supply Side Management (SSM)}

The proposed SSM action is to install a thermal load controller to SANAE IV microgrid. A thermal load controller (TLC) consists of a resistance set and a control system and is used for converting excess energy to heat [15]. Since the thermal load of the base is high, it is appropriate to use a TLC as an energy sink.

It is common practice to utilize energy storage devices in microgrids that include renewable energy sources [16]. When the renewable energy output exceeds the demand, surplus energy would be transferred to the storage and would be used when needed. However, storage devices are very costly for large-scale applications and their efficiency is low due to charging-discharging round-trip losses. It would be even more inconvenient to use storage systems in SANAE IV when the extreme climate conditions are taken into account. Instead, a thermal load controller would utilise the base's thermal capacity as a buffer, equivalent to a thermal energy storage system.

\section{B. Demand Side Management (DSM)}

The proposed DSM action is a demand response program, based on operating the snow smelter at times when renewable energy generation is high. The conventional operating times of the snow smelter will be reconstructed according to the proposed scheme, so that the load of the diesel generator can be reduced and fuel consumption to be decreased. The snow smelter can be defined as a deferrable load since it needs to be supplied with a specific amount of energy, but timing of that supply is flexible.

As it is mentioned before, the snow smelter consists of six $15 \mathrm{~kW}$ heating elements. This means that, per hour, the smelter would be demanding $n^{*} 15 \mathrm{kWh}$ of energy ( $\mathrm{n}^{*} 15 \mathrm{~kW}$ of power), where $\mathrm{n}$ is an integer less than or equal to 6 . We define $15 \mathrm{kWh}$ as quantized "blocks" and the approach is to try to arrange these blocks in a way that constructs a load curve which matches as closely as possible with the renewable generation. A simplistic example is provided in Fig. 1.

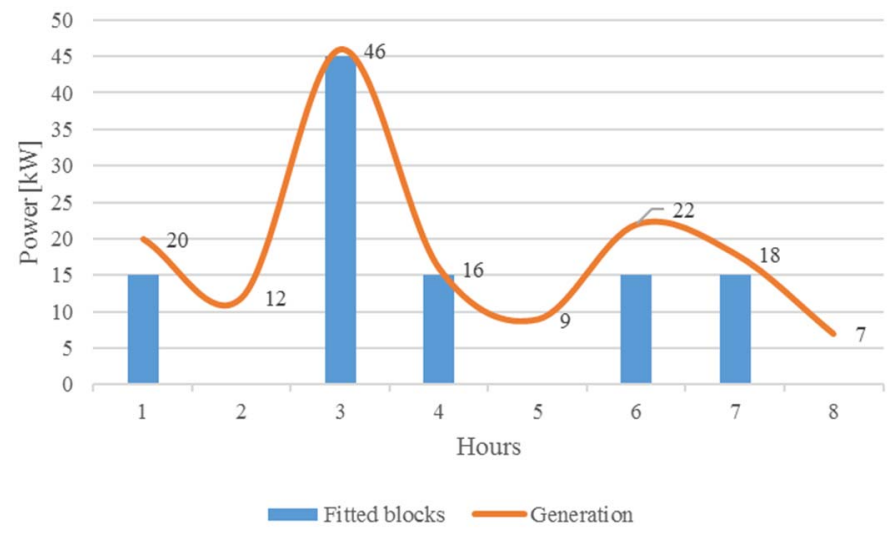

Fig. 1. Fitting snow smelter load "blocks" around renewable generation 
Such an optimisation problem can be formulated as follows. For a given time interval $[a, b]$ :

$$
\begin{gathered}
f\left(n_{i}\right)=\sum_{i=a}^{b}\left|15 n_{i}-g_{i}\right| \\
\min f\left(n_{i}\right)
\end{gathered}
$$

s.t.

$$
\sum_{i=a}^{b} 15 n_{i} \geq E_{S S} \quad n_{i} \in\{0,1,2,3,4,5,6\}
$$

where $n_{i}$ is the number of online heaters and $g_{i}$ is the available renewable power at hour $i . E_{S S}$ is the required energy for the snow smelter for the given time interval, which is calculated by the heat equation:

$$
E_{s s}=\frac{1 k W h}{3600 k J}\left[m c_{\text {snow }}\left(-T_{\text {snow }}\right)+m L_{\text {snow }}+m c_{\text {water }} T_{\text {water }}\right]
$$

where $c_{\text {snow }}$ and $c_{\text {water }}$ are the specific heat of snow and water, $L_{\text {snow }}$ is the latent heat of fusion for snow, $T_{\text {snow }}$ is the initial and $T_{\text {water }}$ is the final temperature of snow and water, respectively, and $m$ is the mass of matter.

\section{Energy management process flowchart}

A flowchart describing the proposed energy management process is shown in Fig. 2.

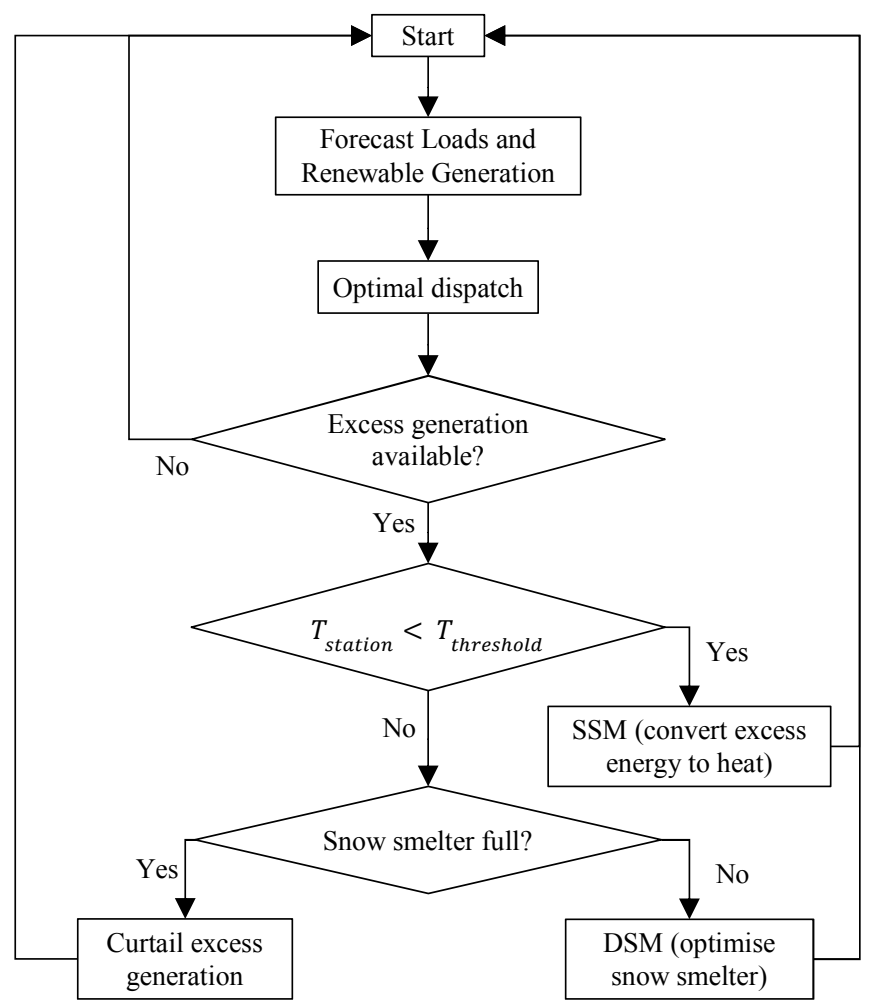

Fig. 2. Energy management process flowchart
The system initially needs to forecast the expected loads and renewable generation, then optimise the dispatch based on the available information. If there is still excess generation, the algorithm checks if the station temperature $T_{\text {station }}$ is sufficiently low, to allow for the excess to be dumped as heat, i.e. perform SSM. If not, the algorithm then checks if the snow smelter is full, in order to dump the excess energy into melting snow. If no more snow can be melted, then the excess generation is curtailed.

\section{System Modelling AND SimULATION}

HOMER (Hybrid Optimization Model Energy Resource) is used for the simulations. Two generic CHP generators are considered, rated at $180 \mathrm{~kW}$. Electrical efficiency of generators has been given as $36.4 \%$. Typical power-to-heat ratio for industrial generators is 0.9 [17], which corresponds to a heat recovery ratio of $40.5 \%$ in this case. A generic $20 \mathrm{~kW}$ gearless wind turbine is also adapted to reflect the renewable penetration.

When it comes to the daily electrical consumption patterns for SANAE IV, the available data is limited. Therefore taking the season of year, daily activities and population into consideration, daily load curves for a standard day are estimated for three different seasons as shown in Fig. 3. Linear regression was used to model thermal loads as a function of ambient temperature.

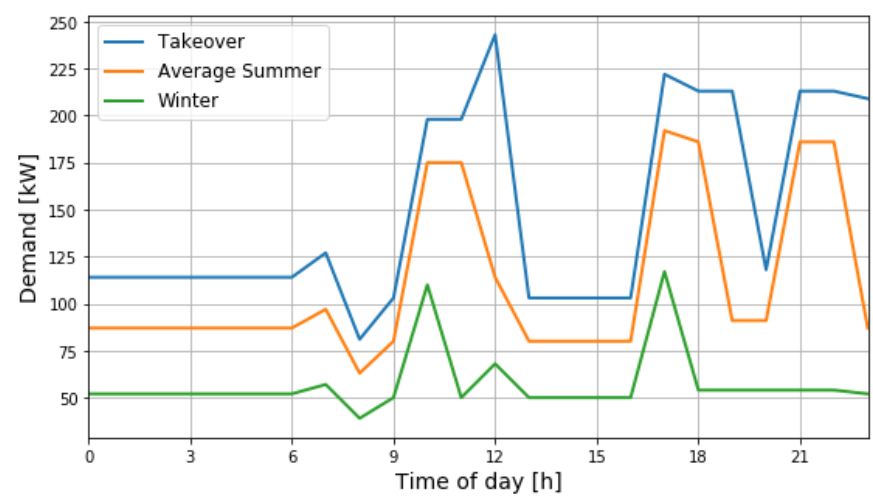

Fig. 3. Estimated daily electrical load curves for different seasons

Simulations have been performed for four different cases, namely base case SSM with Optimal Dispatch of Generation (ODG) only, SSM with Optimal Dispatch of Generation \& Thermal Load Controller (TLC), and SSM with DSM. See Fig. 4 for the HOMER schematic when all the proposed actions are included.

\section{RESULTS AND DISCUSSION}

Fig. 5, 6 and 7 show a summary of the results. The use of the DSM program enabled a $1.45 \%$ decrease in fuel usage when compared to SSM only. It is an important fact since the reduction is achieved while the total demand is actually increased. The specific energy, i.e. $\mathrm{kWh}$ produced per one litre of diesel, has been increased from $5.32 \mathrm{kWh} /$ litre to $5.43 \mathrm{kWh} /$ litre which is equal to a $1.81 \%$ rise. With all the actions included, the proposed energy management strategy offers an $8.30 \%$ decrease in fuel consumption, which is equal to 21,876 litres of SAB. Operating times of generators have been reduced by $9.20 \%$ and the excess electricity production has been eliminated. 


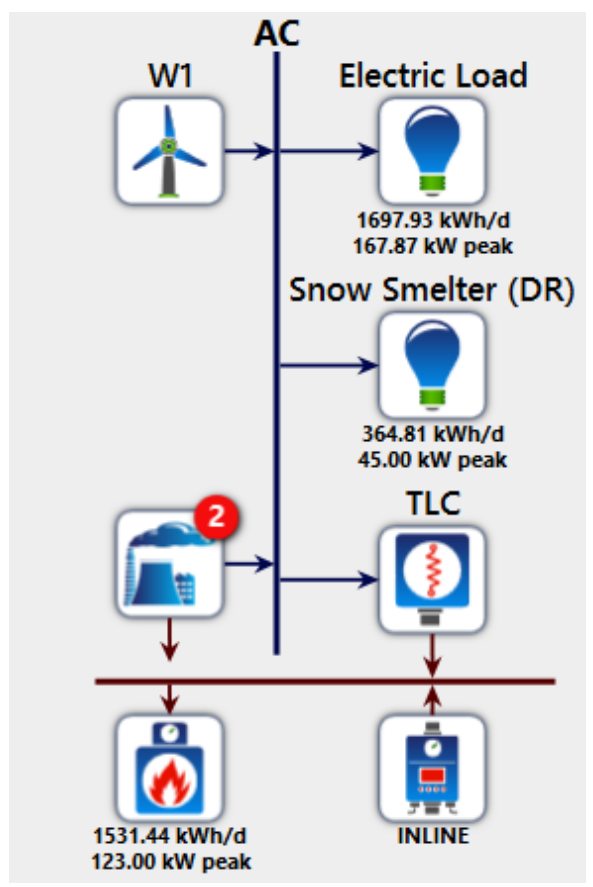

Fig. 4. HOMER schematic of the model.

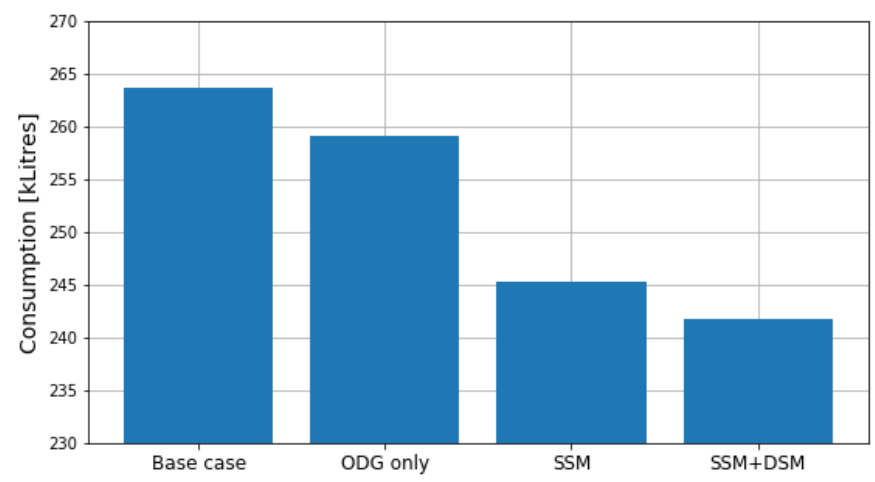

Fig. 5. Annual fuel consumption for various types of energy management actions included

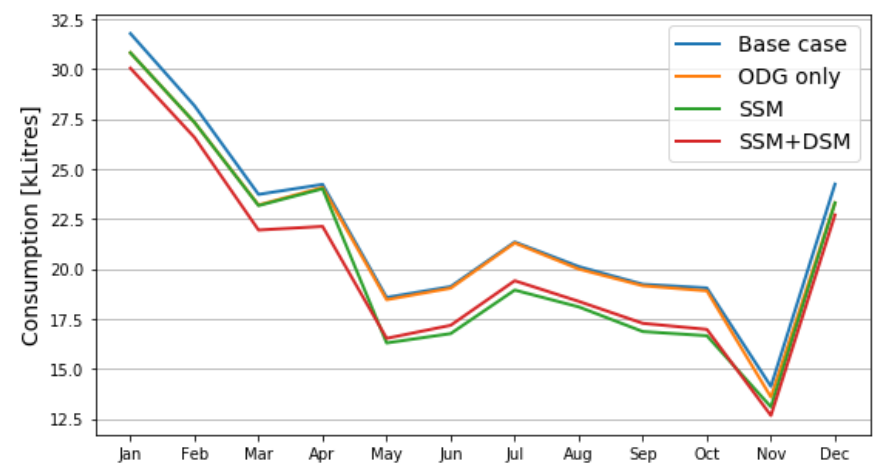

Fig. 6. Monthly fuel consumption for various types of energy management actions included

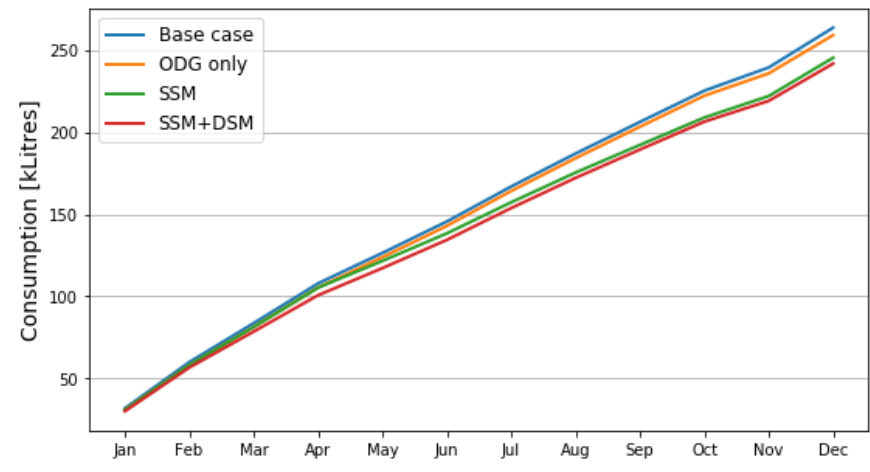

Fig. 7. Cumulative fuel consumption for various types of energy management actions included

One drawback of the proposed methodology is that the startstop counts of diesel generators have been increased by $46.7 \%$ (from 454 to 666), which may reduce the life expectancy of generators if they are not designed for intermittent operation.

\section{CONCLUSIONS}

In this research, the isolated microgrid of the South African Antarctic base SANAE IV has been modelled. An energy management strategy has been proposed which consists of an optimal dispatch of generation algorithm and installation of a thermal load controller in the supply side, as well as a novel demand response algorithm that arranges the snow smelter operating times in the demand side. It is found that an $8.30 \%$ decrease in diesel consumption, i.e. 21,876 litres of fuel, can be achieved through implementing the proposed strategy. The reduction in diesel usage would significantly reduce the substantial fuel purchasing and transportation costs, freeing up resources for meaningful research activities.

\section{REFERENCES}

[1] "Coolantarctica.com," [Online]. Available: https://www.coolantarctica.com/Antarctica\%20fact $\% 20$ file/science/can you_live_in_antarctica.php.. [Accessed 31 May 2018]

[2] "Comnap.aq," [Online]. Available: https://www.comnap.aq/Information/SitePages/Home.aspx. [Accessed 31 May 2018]

[3] T. Tin, B. Sovacool, D. Blake, P. Magill, S. El Naggar, S. Lidstrom, K. Ishizawa and J. Berte, "Energy efficiency and renewable energy under extreme conditions: Case studies from Antarctica," Renewable Energy, vol. 8, no. 35, pp. 1715-1723., 2010

[4] I. Baring-Gould, R. Robichaud and K. McLain, "Analysis of the Use of Wind Energy to Supplement the Power Needs at McMurdo Station and Amundsen-Scott South Pole Station, Antarctica," NREL, 2005

[5] C. Boccaletti, P. Di Felice and E. Santini, "Integration of renewable power systems in an Antactic Research Station," Renewable Energy, no. 62, pp. 582-591, 2014.

[6] T. de Christo, J. Fardin, D. Simonetti, L. Encarnacao and C. de Alvarez, "Design and analysis of hybrid energy systems: The Brazilian Antarctic Station case," Renewable Energy, no. 88, pp. 236-246, 2016.

[7] J. A. Frye, "Performance - Objective Design of a Wind - Diesel Hybrid Energy System for Scott Base, Antarctica," M. Sc., University of Canterbury, 2006.

[8] H. W. Teetz, "Technical and Economic Evaluation of The Utilization of Wind Energy at the SANAE IV Base in Antarctica," M. Sc, University of Stellenbosch, 2002. 
[9] J. N. Stander, "The Specification of a Small Commercial Wind Energy Conversion System for the South African Antarctic Research Base SANAE IV," M. Sc., University of Stellenbosch, 2008.

[10] J. R. Olivier, "Technical and Economic Evaluation of The Utilization of Solar Energy at the SANAE IV Base in Antarctica," M. Sc., University of Stellenbosch, 2005.

[11] "Sanae base - History," [Online]. Available: http://www.sanap.ac.za/sanap_sanae/sanae_history.html. [Accessed 31 May 2018]

[12] "Wind Energy for SANAE IV," [Online]. Available: http://research.ee.sun.ac.za/sanap/about.html. [Accessed 31 May 2018]

[13] J. R. Olivier, "Technical and Economic Evaluation of The Utilization of Solar Energy at the SANAE IV Base in Antarctica," M. Sc., University of Stellenbosch, 2005.
[14] T. Lambert, P. Gilman and P. Lilienthal, "Micropower System Modelling with HOMER," in Integration of Alternative Sources of Energy, John Wiley \& Sons, Inc., 2006, pp. 379-418.

[15] HOMER Energy, "Combined Heat and Power Module," [Online]. Available: https://www.homerenergy.com/products/pro/modules/combined-heatand-power.html. [Accessed 31 May 2018].

[16] G. Platt, A. Berry and D. Cornforth, "What Role for Microgrids?," in Smart Grid, Elsevier Inc., 2012, pp. 185-207.

[17] International Energy Agency, "Combined Heat and Power Report," [Online]. Available: https://www.iea.org/publications/freepublications/publication/chp_repor t.pdf. [Accessed 31 May 2018] 